\title{
Unemployment and ill health: understanding the relationship
}

\author{
Mel Bartley
}

\begin{abstract}
Objective - To review research relevant to understanding the psychological, social, and biological pathways by which unemployment may affect health risk; to consider the importance of four specific mechanisms; and to indicate some directions for future research.

Criteria for inclusion and exclusion of published studies - Studies were chosen to illustrate the development of four major hypotheses regarding the relationship between unemployment and ill health, as well as the present state of knowledge. The review therefore includes some muchcited "classics" drawn from a long time span. Where recent reviews already exist relevant to individual mechanisms, these are referred to. Recent (since 1987) reports were sought by searching the BIDS data base. Particular effort was made to locate studies which enabled alternative hypotheses to be evaluated, and to point out where existing evidence is inconsistent or incomplete, indicating the need for further research.

Conclusions - To understand the relationship between unemployment and ill health and mortality, four mechanisms need to be considered: the role of relative poverty; social isolation and loss of self esteem; health related behaviour (including that associated with membership of certain types of "subculture"); and the effect that a spell of unemployment has on subsequent employment patterns.
\end{abstract}

( E Epidemiol Community Health 1994;48:333-37)

From 1979-86, UK unemployment rose from just over one to more than three million. This increase peaked in 1986, according to official figures, and by September 1987 had been falling for 12 consecutive months. ${ }^{1}$ Even after the autumn stock market crash, unemployment continued to fall during 1989 and reached a "low" of 1.6 million in early 1990. In the light of these trends, it is not perhaps too surprising that after the appearance of a comprehensive review of the evidence on the links between unemployment and physical and mental health, ${ }^{2}$ interest in the topic declined.

Attention has now turned back to the implications of high and rising levels of unemployment for health after three years in which unemployment has once again risen and re- mains at a high level (in contrast to the rather sharp fall as the 1980 s recession bottomed out). Whereas some commentators ${ }^{3}$ maintain that unemployment could be greatly reduced by improved education and training, in the eyes of many policy makers, full employment, or anything like it, is no longer a desirable goal. High levels of joblessness are the "price worth paying" for low inflation and a "flexible" labour market. If high levels of unemployment are to continue as a feature of the British economy, are present benefit rules and levels appropriate? One factor to be considered when answering this is the relationship between unemployment and ill health.

It is no longer seriously argued that there is no such relationship. Lower levels of psychological well being are found in all studies which compared unemployed people, at all ages and in both sexes. ${ }^{5}$ More persuasively, these differences in mental health have been shown to emerge after entry into the labour market in young people showing no such differences while still at school. Mental health improves when young people find jobs. ${ }^{67}$

What of physical health? An estimate, which emerged from 10 years of follow up of men who were unemployed at the 1971 census of England and Wales (the Office of Population Censuses and Survey (OPCS) Longitudinal Study), of a $20 \%$ excess risk of death among those actively seeking work at the census ${ }^{89}$ seems widely accepted. Nor has doubt been thrown on several of the other conclusions of this workthat this is not accounted for by the social class distribution of the unemployed; that a similar excess mortality risk is experienced by wives of unemployed men; and that at times and in regions of higher unemployment, the risk to health is even greater. ${ }^{1011}$ These data from England and Wales have now been supported by data from similar census linked studies in Denmark $^{12}$ and Finland. ${ }^{13}$

Some controversy still exists, however, over the exent to which excess morbidity and mortality in the unemployed might be a result of those in poorer health being at higher risk of unemployment as well as further ill health or death. ${ }^{31415}$ Mortality data can be used to test this hypothesis. In a cohort study, any group selected for physical illness should exhibit high mortality in the early years of follow up which returns towards the level of the rest of the cohort later on as those who are very ill die and the rest recover. ${ }^{89}$. In the census linked studies, this pattern is seen in men who are "permanently sick" but not in the unemployed: 
mortality in the latter group remains high for as much as 10 years of follow up. This does not entirely rule out the possibility that psychological illness, for example, may increase the individual's risk of both unemployment and also of health hazards such as various forms of self destructive behaviour. Such a model of the mechanism relating unemployment to mortality could not, however, account for observed excess deaths from lung cancer in unemployed men, or ischaemic heart disease in their wives found in the Longitudinal Study. ${ }^{89}$

Attention is accordingly now focussed on the mechanisms by which these relationships may be produced. Attempts to clarify the question of mechanism may be divided into four types of explanation: (1) poverty, (2) stress, (3) health related behaviour, and (4) the effect of unemployment on the rest of the work career. As mentioned above, selection cannot be ruled out as a partial explanation, but few would argue that this is the dominating factor. An element of selection can be acknowledged to combine with other mechanisms.

\section{Poverty}

Some of the most recent research into the relationship between unemployment and ill health has argued for putting poverty back into the centre of the inquiry. ${ }^{16}$ Many studies link the health effects of unemployment directly to financial problems. Jackson and Warr report that the proportional change in family income between employment and unemployment predicted subjects' scores on the General Health Questionnaire (GHQ), a widely used measure of psychological health. ${ }^{17}$ In studies by White $e t$ $a l$, long term unemployed people who had had to borrow money in the past year had a risk of depression, as measured by the GHQ score (4.5), which was more than double that of those who did not have to borrow $(2 \cdot 0)$. These researchers also found that those obliged to borrow were also more likely to report a deterioration in physical health. ${ }^{3}$ Others have documented the ways in which increasing financial pressures, as savings are used up and worn out items need to be replaced, are responsible for the growing inactivity and social isolation of many unemployed people. ${ }^{1819}$ In the OPCS/ Department of Social Security (DSS) survey of living standards in unemployment, GHQ scores were related to a ratio of savings to debt. ${ }^{20}$ In the MRC's 1946 Cohort Study, after financial hardship was controlled for, the relationships between unemployment and psychological symptoms in both men and women were weakened or disappeared. ${ }^{21}$

These British findings are echoed in other countries. Kessler et al found that financial strain was the strongest mediating factor between unemployment and reported ill health in their American study, and was far more important than reduced social integration or an increased number of life events. ${ }^{22}$. A Dutch study found similarly that present or anticipated financial problems were the mediating factors between unemployed status and reported health problems in both men and women $;{ }^{23}$ the other important factor was loneliness. ${ }^{24}$ In a study in Malmo, Sweden, the relationship between threatened redundancy and psychological and physiological health measures seemed to vary according to the degree of future financial uncertainty. Male shipyard workers aged over 58 who were threatened with redundancy but knew they would be offered relatively generous early retirement settlements experienced no deterioration in psychological health and a rise of only $0.09 \mathrm{mmol} / 1$ in total cholesterol. In younger men with no such reassuring prospects, however, the cholesterol concentration rose by $0.28 \mathrm{mmol} / 1$. By contrast, in the controls who were not involved in the shipyard closure, the rise in men over 58 years was greater than that in younger men. ${ }^{25}$

Eventually, it seems, many of the unemployed adapt to straitened financial and social circumstances. Several studies agree that there does not appear to be further deterioration in their psychological well being after a period of between one year and 18 months. ${ }^{26-28}$ However, it is likely that there is a cost associated with this adaptation in terms of lowered expectations of oneself, and perhaps a degree of alienation and cynicism. In Warr and Jackson's study, GHQ scores did not deteriorate between 18 and 27 months of continuous unemployment, although they remained at a level far above those of comparable employed samples. ${ }^{29}$ The authors compare the adaptive process to that found in institutionalised inmates of prisons or hospitals.

It is important to understand the political and economic importance of the level of unemployment benefit when addressing questions about the effect of living standards during unemployment on health and how this might be alleviated. According to some opinion within present economic orthodoxy, the level of benefit should be sufficient to maintain physical subsistence, without being a disincentive to the search for work. ${ }^{30}$ In order for this to happen, the value of unemployment benefit must be below that of the lowest wage rate that employers are willing to pay. If the level of pay at which an unemployed person will accept new work - the "reservation wage" - is too high, employers will not take them on. If benefit levels are too high, the state is therefore contributing to the problem. According to these "supply side arguments", a high level of benefits causes a high rate of unemployment. ${ }^{3132}$ Accordingly, benefits were cut in a number of ways from the early 1980s. These measures were indeed followed by a decrease in the real value of the lowest wages, and a general redistribution of income away from the poorest, so that between 1979 and 1991, while the average household experienced an increase in real income of $36 \%$, that of the poorest tenth fell by $14 \%$ after housing costs. ${ }^{33}$

\section{Unemployment as a stressful life event}

If the threat of unemployment is to act as a disincentive to wage militancy and accomplish various other objectives relating to "labour discipline", then it has to be regarded as an unwel- 
come experience. It is not surprising therefore that research shows job-loss to be highly stressful, characterised as a form of bereavement. ${ }^{34}$ In modern welfare states, despite the evidence of severe poverty, the threat of starvation and physical privation are no longer thought to accompany the loss of paid work. ${ }^{143536}$ Many researchers have suggested that the reason unemployment is still a threatening experience is that work has a number of non-financial benefits to the individual. Jahoda first proposed a set of such benefits, which she termed the "latent consequences of employment". These included giving a time structure to the day, self esteem, and the respect of others. ${ }^{37-39}$ Warr has developed a similar "vitamin theory" of the benefits of work for mental health, which include physical and mental activity, use of skills, decision latitude, interpersonal contact, social status, and "traction"-a reason to go on through the day and from one day to the next. ${ }^{404}$

What is the relative importance of financial versus social-psychological factors in the undoubted deterioration in psychological health experienced by most unemployed people? Much of the evidence comes from Scandinavia where benefits are relatively generous. A study of welfare clients in Stockholm (men with irregular work histories and a variety of problems which required frequent social service assistance) found that among unemployed clients there were some who nevertheless reported higher levels of activity, social contacts, and social status, and these had higher levels of psychological well being as measured by the GHQ. Those who were employed, even in low paid casual jobs, were all more active and integrated (and psychologically healthier) than the unemployed. ${ }^{41}$ Among unemployed industrial workers in Finland, those who regained work experienced a considerable improvement in psychological health regardless of their financial circumstances either before or after reemployment. ${ }^{4243}$ Italian workers laid off from their jobs experienced raised amounts of both psychological and physical illness despite receiving the whole of their normal wage. ${ }^{44}$ These studies provide evidence of the nonfinancial benefits of work for psychological health.

"Stress" is held to affect physical health rather further down the line, as a result perhaps of chronically increased levels of anxiety. ${ }^{45}$ However, not all research results fit neatly into a model of disease as caused by stress resulting from the experience of unemployment itself. In fact one of the most consistently replicated findings in this area is that health begins to be affected at the time when people anticipate umemployment but are still at work. ${ }^{46-48}$ It seems that in terms of physical (as opposed to psychological) health, not only is there no further deterioration after the job has actually been lost, but there is little sign of improvement on re-employment. ${ }^{47} 49$

Thus, although there is considerable support for the idea that unemployment affects health in a manner similar to other stressful life events, there is still a need to explore other mechanisms.

\section{Health related behaviour}

There is evidence that unemployment is associated with some forms of health damaging behaviour, although disagreement exists as to whether behaviour or job loss comes first. In some studies, unemployed people seem to be heavier smokers ${ }^{5051}$ and drinkers, ${ }^{52}$ though others disagree. ${ }^{53}$ There is no evidence that this difference is caused by people taking up or increasing their consumption during periods of unemployment; ${ }^{51}$ if anything, the amount consumed declines, presumably as a result of financial pressures. ${ }^{54}$ However, people seem to find it harder to give up smoking altogether if unemployed, despite the fact that unemployed men have been found to be just as well informed as the employed about the dangers of smoking and equally likely to feel they should give up..$^{55}$ Middle aged men in the Regional Heart Study who later lost employment were more likely to be heavy drinkers at screening, but were likely then to reduce the amount they drank while not employed. ${ }^{51}$ But heavy drinking in young men in the 1958 cohort was more prevalent among those unemployed for over six months. ${ }^{56}$ In the Scottish Heart Health Study both heavy drinking and abstention were more common in unemployed men $^{57}$ than in the employed. These findings are consistent with both the decay of normal social activity (often involving light or moderate alcohol consumption) that commonly accompanies unemployment, and with the hypothesis that heavy drinking and tobacco may be used as a way of dealing with stress.

By its nature, the relationship between unemployment and illegal drug taking is difficult to investigate. Young unemployed people in Lothian region had more experience of drugs, reflecting national trends. ${ }^{53}$ A study of young people in Norway produced similar findings but concluded that drugs were not being used to combat stress; rather drug use was part of the adoption of an alternative cultural identity. ${ }^{58}$

More directly self destructive behaviour among unemployed men has been widely investigated. ${ }^{59}$ In the OPCS Longitudinal Study, men unemployed at the 1971 census had a standardised mortality ratio for suicide of 236: this excess risk was greatest in those aged 36 to $44 .^{8}$ More recently, the possible link between unemployment and national trends in suicide among younger men have given cause for concern. ${ }^{60}$ However, male suicide continued to rise as unemployment fell in the late 1980 s. $^{61}$ Parasuicide ("attempted suicide") is also higher in unemployed men. ${ }^{62-64}$ There seems to be agreement that it is not unemployment per se which precipitates suicidal behaviour. ${ }^{606}$ Rather, as Kessler et al have also found in their American studies, unemployment increases the likelihood of other adverse life events and lessens the psychological and social resources needed to cope with these. ${ }^{22}$ Longtitudinal research in England and Wales also shows that a spell of unemployment may have "knock on effects" such as loss of home and relationship breakdown. ${ }^{66}$ 
Unemployment in the work history

There is evidence to suggest that in order fully to understand the links between unemployment, ill health, and mortality it is necessary to look beyond the experience of unemployment itself. A spell of unemployment is not usually a mere interlude, however unpleasant, which has no effect once it is over ${ }^{67-69}$ On the contrary, we now know that losing a job can precipitate a self perpuating series of negative events well into the future, even after work has been regained. ${ }^{6670-72}$ The risk of unemployment is not randomly distributed. ${ }^{73}$ On the contrary, a relatively small proportion of the economically active population experience the majority of time unemployed. ${ }^{74}$ Furthermore, once a person has become unemployed for the first time, their risk of further unemployment is greatly increased..$^{73}$

It may be argued that the association of unemployment with raised mortality over the longer term is as much a consequence of the more general labour market experience of those at high risk of job loss. Recent British and American studies indicate that not all jobs, regardless of quality, can protect physical or mental health. In contrast to the Scandinavian studies quoted above, studies of school leavers in Australia show that unsatisfactory jobs can be as depressing as unemployment. ${ }^{75-77}$ In the British Social Change and Economic Life Initiative, those with insecure work who had been obliged to take lower status jobs in the recent past had a score on the GHQ that was not significantly different from the unemployed. ${ }^{78}$ Insecure jobs also tend to be ones which involve high exposure to work hazards of various kinds. ${ }^{79}$

\section{Conclusion}

Research has considerably advanced our understanding of the ways in which health may be related to unemployment. The impact on psychological health seems to be at least partly mediated through poverty and financial anxiety, although Scandinavian and Italian data suggest that stigma and social isolation also play an independent role. Financial problems will act partly by increasing the frequency of stressful life events associated with debt, and possibly by the effect on diet and the quality of the home environment. For many of the unemployed, social activity and participation-and therefore social support-fall dramatically. Research does not show conclusively whether this is because of psychological changes or financial hardship, but whichever is the case, the result is an unfortunate synergism of increased frequency of life events and reduced support. New social networks may eventually be formed or discovered by the unemployed individual, preventing further psychological deterioration; however, in some cases these networks may involve groups who have withdrawn from the norms and values of the mainstream of society.

Unemployment may affect physical health via a "stress" pathway involving physiological changes such as a raised cholesterol concentration and lowered immunity. The increase in mortality risk over the longer term is also found in the Scandinavian countries, where benefits are more generous than in the UK. This strengthens the likelihood that the relationship between unemployment and physical health may be partly attributable to the effects of relative disadvantage in those at high risk of job loss as opposed to poverty in any absolute sense. In all countries, low pay and exposure to hazards are associated with job insecurity, and perhaps with the adoption of lifestyles in which a higher degree of risk is accepted. ${ }^{80}$ When the unemployed are compared not with all employed but with people in the sorts of occupations where the risk of unemployment is high, far less difference is found in measures of either physical or psychological health.

Research can therefore build upon the foundations laid in the 1980s. More work is needed to examine patterns of employment and unemployment over time: such work has begun using the 1958 British Birth Cohort, who passed through the recession of the 1980s when aged between 23 and $33 .{ }^{81}$ We also need to know more about the ways in which people adopt different social networks during long term unemployment and the effect this may have on health behaviours. "Counter cultures" are not always "unhealthy", in some cases quite the reverse. ${ }^{82}$ Studies are also needed which compare the experience of unemployment in countries with higher and lower levels of benefit and retraining, paying special attention to self esteem and social support. Future research will no doubt continue to improve our ability both to understand the relationship between unemployment and health, and to contribute to the design of policy.

I thank Professor Adrian Sinfield and Professor Mike Wadsworth for comments on an earlier draft of this paper.

1 Lawlor J. Monthly unemployment statistics: maintaining a consistent series. Employment Gazette 1990; December: consis

2 Smith R. Unemployment and health: a disaster and a challenge. Oxford: Oxford University Press, 1987.

3 White M. Against unemployment. London: Policy Studies Institute, 1991

4 Warr PB. Job loss, unemployment and psychological wellbeing. In: Allen V, van de Vliert E eds. Role transitions. New York: Plenum Press, 1984

5 Warr $P$. Twelve questions about unemployment and health. In: Roberts B, Finnegan R, Gallie D eds. New approaches to economic life. Manchester: Manchester University Press, 1985.

6 Banks MH, Jackson PR. Unemployment and the risk of minor psychiatric disorder in young people: cross-sectional and longitudinal evidence. Psychol Med 1982;12:789-98.

7 Tiggeman $M$, Winefield AH. The effects of unemployment on mood, self-esteem, locus of control and depressive effect on mood, self-esteem, locus of control and depressive
of school leavers. $\mathcal{F}$ Occup Psychol 1984;57:33-42.

of school leavers. $\mathcal{F}$ Occup Psychol 1984;57:33-42.
8 Moser KA, Fox AJ, Jones DR. Unemployment and mortality in the OPCS Longitudinal Study. Lancet tality in the

9 Moser K, Goldblatt P, Fox J, Jones D. Unemployment and mortality. In: Goldblatt PO ed. Longitudinal study: mormortality. In: Goldblatt PO ed. Longitudinal study: mor

10 Moser KA, Fox AJ, Jones DR, Goldblatt PO. Unemployment and mortality: further evidence from the OPCS longitudinal study 1971-81. Lancet 1986;i:365-7.

11 Moser KA, Goldblatt PO, Fox AJ, Jones DR. Unemployment and mortality: comparison of the 1971 and 1981 longitudinal study samples. $B M \mathcal{F}$ 1987;294:86-90.

12 Iversen L, Andersen O, Andersen PK, Christoffersen K, Keiding N. Unemployment and mortality in Denmark. BMF 1987;295:879-84.

13 Martikainen $P$. Unemployment and mortality among Finnish men. $B M \mathcal{1}$ 1990;301:407-11.

14 Valkonen T, Martikainen P. The association between unemployment and mortality: causation or selection? Paper to IUSSP Seminar Premature adult mortality in developed countries. Taormina, Italy 1-5 June 1992

15 Claussen B, Bjorndal A, Hort PF. Health and re-employment in a 2-year follow-up of long term unemployed. $\mathcal{f}$ Epidemiol Community Health 1993;47:14-18. 
16 Fryer D. A plea for a greater emphasis on the role of poverty in psychological research on unemployment and mental health in the social context. In: Verhaar CHA, Janussen JG eds. On the mysteries of unemployment Amsterdam: Kluwer Academic Publishers, 1992

17 Jackson PR, Warr PB. Unemployment and psychological illhealth: the moderating role of duration and age. Psychol Med 1984;14:605-14.

18 Bradshaw J, Cooke K, Godfrey C. The impact of unemployment on the living standards of families. Fournal of Social ment on the living stan
Policy 1983;12:433-52.

19 Clarke M. The unemployed on supplementary benefit: living standards and making ends on a low income. Fournal of Social Policy 1978;7:385-410.

20 Heady $\mathrm{P}$, Smyth $\mathrm{M}$. Living standards during unemployment. London: HMSO, 1989

21 Rodgers B. Socio-economic status, employment and neurosis. Soc Psychiatry Psychiatr Epidemiol 1991;26:104-14.

22 Kessler RC, Turner JB, House JS. Effects of unemploymen on health in a community survey: main, modifying and mediating effects. Fournal of Social Issues 1988;44:69-85.

23 Leeflang RLI, Klein-Hesselink DJ, Spruit IP. Health effects of unemployment II: men and women. Soc Sci Med 1992;34:351-62.

24 Leeflang RLI, Klein-Hesselink DJ, Spruit IP. Health effects of unemployment I: Long term unemployed men in a rural and an urban setting. Soc Sci Med 1992;34:341-50.

25 Mattiasson I, Lindgarde F, Nilsson JA, Theorell T. Threats of unemployment and cardiovascular risk factors: longituof unemployment and cardiovascular risk factors: longitu-
dinal study of quality of sleep and serum cholesterol concentrations in men threatened with redundancy. $B M \mathcal{F}$ concentrations in

26 Warr PB, Jackson PR. Factors influencing the psychological impact of prolonged unemployment and of re-employment. Psychol Med 1985;15:795-807.

27 Banks MH, Ullah P. Youth unemployment : social and psychological perspectives. Department of Employment Research Paper no 61. London: HMSO, 1987

28 Hamilton VL, Hoffman WS, Broman CL, Rauma D. Unemployment, distress and coping: a panel study of autoworkers. Fournal of Personality and Social Psychology 1993;65:234-47.

29 Warr P, Jackson P. Adapting to the unemployed role: a longitudinal investigation. Soc Sci Med 1987;25:1219-24.

30 Gaffikin F, Morrisey M. The new unemployed: joblessness and poverty in the market economy. London and New Jersey: Zed Books, 1992

31 Minford P. Corporatism, the natural rate and productivity, in: Philpot J ed. Trade unions and the economy: into the 1990s. London: Employment Institute, 1990.

32 Benjamin DK, Kochin LA. Searching for an explanation of unemployment in interwar Britain. Fournal of Political Economy 1979;82:441-78.

33 Hansard written answers 18 October 1993, cols 166-7, quoted in A Sinfield ed. Poverty, inequality and justice (Edinburgh: New Waverley Papers no 6, 1993.

34 Fagin L, Little M. The forsaken families. Harmondsworth: Penguin Books, 1984.

35 Gravelle HSE. Does unemployment kill? Nuffield/York Portfolio no 9, 1985 .

36 Stern J. Does unemployment really kill? New Society 1982; June 10:421-2.

37 Jahoda $M$. Incentives to work-a study of unemployed adults in a special situation. Occupational Psychology adults in a

38 Fryer D. Monmouthshire and Marienthal: sociographies of two unemployed communities. In: Fryer $D$ and Ullah $P$ eds. Unemployed people. Milton Keynes: Open University Press, 1987.

39 Jahoda M. The impact of unemployment in the 1930 s and the 1970s. Bulletin of the British Psychological Society 1979;32:309-14

40 Warr PB. Work, unemployment and mental health. Oxford: Oxford University Press, 1987.

41 Isakson $\mathrm{K}$. Unemployment and mental health and the psychological functions of work in male welfare clients in Stockholm. Scand $\mathcal{f}$ Soc Med 1989;17:165-9.

42 Lahelma E. Paid employment, unemployment and mental well-being. Psychiatrica Fennica 1992;23:131-44.

43 Lahelma E. Unemployment and mental well-being: elaboration of the relationship. Int $\mathcal{f}$ Health Serv 1992;22:261 74.

44 Rudas N, Tondo L, Musio A, Mosia M. Unemployment and depression. Results of a psychometric evaluation. Minerva

45 Kaplan HB. Social psychology of the immune system: a conceptual framework and review of the literature. Soc $\mathrm{Sc}$ Med 1991;33:909-23.

46 Cobb S, Kasl SC. Termination: the consequences of job loss. Cincinnati: DHEW-NIOSH Publication no 77-224, US National Institutes for Occupational Safety and Health 1977

47 Beale $\mathrm{N}$, Nethercott S. Job-loss and family morbidity: a study of a factory closure. $\mathcal{F} R$ Coll Gen Pract 1985;35:510 14.

48 Iversen L, Klausen H. The closure of the Nordhavn shipyard. Copenhagen: Institute of Social Medicine. Kobenhavns Universitet Publikation 13, FADL, 1981.
49 Beale $\mathrm{N}$, Nethercott $\mathrm{S}$. The health of industrial employees four years after compulsory redundancy. $\mathcal{f} R$ Coll Gen Pract 1987;37:390-4.

50 Cook DG, Cummins RO, Bartley MJ, Shaper AG. Health of unemployed middle aged men in Great Britain. Lancet 1982;i:1290-4.

51 Morris JK, Cook DG, Shaper AG. Non-employment and changes in smoking, drinking and body weight. $B M \mathcal{J}$ 1992;304:536-41.

52 Wilson P. Drinking in England and Wales. London: HMSO, 1980.

53 Peck DF, Plant MA. Unemployment and illegal drug use: concordant evidence from a prospective study and national trends. $B M \mathcal{F}$ 1986;293:929-32.

54 Morris JK, Cook DG. A critical review of the effect of factory closures on health. Br f Industrial Med 1991;48:1-8.

55 Lee AJ, Crombie IK, Smith, WCS, Tunstall-Pedoe HD. Cigarette smoking and employment status. Soc Sci Med 1991;32:1309-12.

56 Power C, Esthaugh V. Employment and drinking in early adulthood: a longitudinal perspective. $\mathrm{Br} \mathscr{f}$ Addict 1990;85:487-94.

57 Lee AJ, Crombie IK, Smith WC, Tunstall-Pedoe HD. Alcohol consumption and unemployment among men: the Scottish Heart Health Study. Br $\mathscr{f}$ Addict 1990;85:115670.

58 Hammer T. Unemployment and use of drug and alcohol among young people: a longitudinal study in the general among young people: a longitudinal study

59 Platt S. Unemployment and suicidal behaviour: a review of the literature. Soc Sci Med 1984;19:93-115.

60 Pritchard C. Is there a link between suicide in young men and unemployment? Br F Psychiatry 1992;160:750-6.

61 Charlton J, Kelly S, Dunnell K, Evans B, Jenkins R. Suicide deaths in England and Wales: trends in factors associated with suicide deaths. Population Trends 1993;71:34-42.

62 Platt S, Kreitman N. Trends in parasuicide and unemployment among men in Edinburgh: 1968-82. BMF 1984;289: 1029-32.

63 Platt S, Kreitman N. Parasuicide and unemployment among men in Edinburgh: 1968-1982. Psychol Med 1985;15:113-

64 Hawton K, Rose N. Unemployment and attempted suicide among men in Oxford. Health Trends 1986;18:29-32.

65 Platt S. Parasuicide and unemployment. Editorial. $B r f$ Psychiatry 1986;149:401-5.

66 Fox AJ. Socio-demographic consequences of unemployment: a study of changes in individuals' characteristics between 1971 and 1981. London: City University, Social Statistics Research Unit, mimeo, 1986

67 Daniel WW. How the unemployed fare after they find new jobs. Policy Studies 1983;3:246-60

68 Daniel WW. The unemployed flow. London: Policy Studies Institute, 1990. chap 2 \& 3.

69 Ferman L. Gardner J. Economic deprivation, social mobility and mental health. In: Ferman L, Gordus J eds. Mental health and the economy. Kalamazoo, Michigan: WE Upjohn Institute for Employment Research, 1979.

70 Harris CC. Redundancy and recession. Oxford: Blackwell, 1987

71 White M. Long term unemployhment and labour markets. London: Policy Studies Institute, 1983.

72 Westergaard J, Noble I, Walker A. After redundancy: the experience of economic insecurity. Cambridge: Polity Press,

73 Sinfield RA. What unemployment means. Oxford: Martin Robertson, 1981.

74 Stern J. Who bears the burden of unemployment? In: Beckermann W ed. Slow growth in Britain. Oxford: Clarendon, 1979.

75 Winefield AH, Tiggeman M, Goldney RD. Psychological concomitants of satisfactory employment and unemployment in young people. Soc Psychiatry Psychiatr Epidemiol 1988;23:149-57.

76 Winefield AH, Tiggeman M, Goldney RD. The psychological impact of unemployment and unsatisfactory employment in young men and women: longitudinal and ployment in young men and women: longitudinal

77 Graetz B. Health consequences of employment and unemployment: longitudinal evidence for young men an women. Soc Sci Med 1993;36:715-24.

78 Burchell $B$. Who is affected by unemployment? Job insecurity and labour market influences on psychological health In: Gallie D, Marsh C, Vogler C eds. Unemployment and social change. Oxford: Blackwell, 1994.

79 Robinson JC. Job hazards and job security. $\mathcal{f}$ Health Polit Policy Law 1986;11:1-18.

80 M Lajer. Unemployment and hospitalization among bricklayers. Scand f Soc Med 1982;10:3-10.

81 Wadsworth MEJ, Bartley MJ, Montgomery SM, Cook DG, Brynner J. Precursors and outcomes of unemployment in a national birth cohort study. London: Economic and Social Research Council Study no R000234697. City University.

82 Charles N, Kerr M.Women, food and families. Manchester: Manchester University Press, 1988. 